\title{
Microbiota transplantation: concept, methodology and strategy for its modernization
}

\author{
Faming Zhang ${ }^{1,2,3 \bowtie}$ (D), Bota Cui ${ }^{1,2}$, Xingxiang $\mathrm{He}^{4}$, Yuqiang $\mathrm{Nie}^{5}$, Kaichun $\mathrm{Wu}^{6,7}$, Daiming Fan ${ }^{6,7}$, \\ FMT-standardization Study Group \\ ${ }^{1}$ Medical Center for Digestive Diseases, The Second Affiliated Hospital of Nanjing Medical University, Nanjing 210011, China \\ ${ }^{2}$ Key Lab of Holistic Integrative Enterology, Nanjing Medical University, Nanjing 211166, China \\ 3 Division of Microbiotherapy, Sir Run Run Shaw Hospital, Nanjing Medical University, Nanjing 211166, China \\ ${ }^{4}$ Department of Gastroenterology, The First Affiliated Hospital of Guangdong Pharmaceutical University, Guangzhou 510080, \\ China \\ ${ }^{5}$ Department of Gastroenterology, Guangzhou Digestive Disease Center, Guangzhou First People's Hospital, Guangzhou \\ Medical University, Guangzhou 510180, China \\ ${ }^{6}$ State Key Laboratory of Cancer Biology \& Xijing Hospital of Digestive Diseases, Fourth Military Medical University, Xi'an \\ 710032, China \\ ${ }^{7}$ National Clinical Research Center for Digestive Diseases, Xi'an 710032, China \\ $\triangle$ Correspondence: fzhang@njmu.edu.cn (F. Zhang)
}

Received February 28, 2018 Accepted April 8, 2018

\begin{abstract}
Fecal microbiota transplantation (FMT) has become a research focus of biomedicine and clinical medicine in recent years. The clinical response from FMT for different diseases provided evidence for microbiota-host interactions associated with various disorders, including Clostridium difficile infection, inflammatory bowel disease, diabetes mellitus, cancer, liver cirrhosis, gutbrain disease and others. To discuss the experiences of using microbes to treat human diseases from ancient China to current era should be important in moving standardized FMT forward and achieving a better future. Here, we review the changing concept of microbiota transplantation from FMT to selective microbiota transplantation, methodology development of FMT and stepup FMT strategy based on literature and state experts' perspectives.
\end{abstract}

KEYWORDS selective microbiota transplantation, microbiome, bacteria, Clostridium difficile, inflammatory bowel disease, step-up fecal microbiota transplantation, perspectives

\section{INTRODUCTION}

Fecal microbiota transplantation (FMT), a concrete evidence proving the role of microbiota in many diseases, has recently become a research focus in biomedicine and clinical medicine (Khoruts and Sadowsky 2016; Lynch and Pedersen 2016; Vindigni and Surawicz 2017). It has been approved as a standard therapy for recurrent Clostridium difficile infection (CDI) by official guidelines (Surawicz et al., 2013). Besides, trials have revealed its potential role in dealing with refractory ulcerative colitis (Cui et al., 2015b; Kellermayer et al., 2015; Moayyedi et al., 2015; Rossen et al., 2015), Crohn's disease (Zhang et al., 2013; Cui et al., 2015a; Shimizu et al., 2016; Bak et al., 2017; He et al., 2017a, b), constipation (Tian et al., 2016), irritable bowel disease (IBS) (Johnsen et al., 2018), liver disease (Kao et al., 2016; Bajaj et al., 2017; Philips et al., 2017; Ren et al., 2017), blood disease (Kakihana et al., 2016; Spindelboeck et al., 2017), autism (Kang et al., 2017) and epilepsy (He et al., 2017a). According to the data on clinicaltrials.gov., more than 200 trials have been or are being conducted by the end of March 2018, most in the past two years. These trials are mainly focused on indications beyond $\mathrm{CDI}$, such as inflammatory bowel disease (IBD). Only a few are designed to analyze the 
methodology, clinical decision, safety and cost-efficacy of FMT. A multidisciplinary survey by a group of international clinicians (Stallmach et al., 2018) showed the different perceptions on the use of FMT in IBD patients. More questions on indications beyond CDI and IBD remain unanswered. We have stepped on the long journey of standardizing FMT. In this review, we will discuss the changing concept, methodology development, management strategy of microbiota transplantation from literature and propose our perspectives.

\section{EXPERIENCES OF USING FECAL MICROBIOTA IN HISTORY}

FMT is a breakthrough not in technological or theoretical research, but in medical recognition. The sequencing of microbiota, bioinformatics technology and holistic understanding on microbiome provided new intuitionistic evidence for indicating the complex community-intrinsic properties (Dubilier et al., 2015; Madsen et al., 2017). However, indepth researches on microbiota are very limited. In a recent study, the Yin-Yang theory (Yin and Yang) originating from traditional Chinese medicine has been proposed to explain the complex ecosystem of gut microbiota (Gibson et al., 2014; Wu et al., 2016; Starkel et al., 2018). According to this theory, the Yin-Yang balance is established between the harmful and beneficial microbial cells in the intestine, a process in which two contradictory forces complement and give rise to each other (Cui and Zhang 2018). Once this balance collapses, pathogens will invade and diseases will occur.

The history of using the stool of the healthy to treat human diseases can date back to the fourth century in China (Zhang et al., 2012b). In Dong Jin Dynasty (AD 300-400 years), Hong $\mathrm{Ge}$, who composed the emergency medicine book Zhou Hou Bei Ji Fang (Ge 2000), described the details of using fecal suspension for serious disorders, including food poisoning, "Wen Bing" (febrile disease) and "Shang Han" (typhoid fever). Therefore, to our knowledge, this book is the first record of using human feces to treat human diseases (Zhang et al., 2012b). The ancient medical history of FMT was confirmed by the following criteria: (1) the delivered materials are taken from human fecal matter; (2) the administration route is the digestive tract; (3) the efficacy is caused by microbiota from the fresh fecal water or fermented fecal matter according to the modern medicine; (4) the recorded prescription, methods, indications and efficacy in ancient literature are clear enough to be identified. Ge clearly recorded this medical use in his book, which suggesting that FMT might have been used in folk medicine long before his era. Expressions like "Wen Bing" and "Shang Han" were then used to classify diseases. "Wen Bing" and "Shang Han" with diarrhea, bloody and purulent stool were classified as refractory conditions in Zhou Hou Bei Ji Fang (Li 2011). According to Ben Cao Gang Mu authored by Shizhen Li in 1578 , fresh or fermented human fecal water could be used for "Wen Bing" with super-high fever, poisoning, abscess, phlegm, stagnated food, or "internal heat" (Li 2011). The book Chong Ding Tong Su Shang Han Lun (Revised Common Discussion of Cold Pathogenic Febrile Disease) (Xu 2011) documented that fecal solution or children's feces could be used to treat "Shang Han" with serious diarrhea. This fecal therapy has also been used for refractory diseases by some elder-generation physicians in recent decades in China. The long tradition of using fecal therapy in China might contribute the high acceptance of FMT by Chinese physicians according to Yang's survey in 2014 (Ren et al., 2016). In 1958, Eiseman et al. reported in English the use of fecal enemas for patients with severe pseudomembranous colitis (Eiseman et al., 1958). In 2013, FMT was for the first time coined into the treatment guidelines on recurrent CDI (Surawicz et al., 2013). Accumulating evidence about FMT opens a new window into the treatment of microbiota associated diseases (Table 1).

\section{THE CHANGE IN USING MICROBES TO TREAT DISEASES FROM MICROBE TO MICROBIOTA}

Microbiologists have isolated many bacteria and used them as probiotics in the last century. The use of bacteria as probiotics has a long history (Brodmann et al., 2017). However, the clinical benefit of using a single species of bacteria is limited (Miller et al., 2016). A single microbe has a weak ability in the prevention and treatment of human diseases, though researches have proven its efficacy in standard animal models (Gibson et al., 2017). The different clinical response between using probiotics and microbiota is the core significance of microbiota in human health. Therefore, new microbes and multiple species are being explored for remodeling gut microbiota. Andrews and Borody for the first time reported that a mixture of 18 strains of probiotics could relieve chronic constipation and IBS (Andrews and Borody 1993). The microbial ecosystem therapeutic (MET-1, or "RePOOPulate") in pilot trials showed an attractive response (Petrof et al., 2013; Martz et al., 2017). The concept of using microbes to treat disease is changing from single species to microbiota (Fig. 1) based on the clinical findings. The use of the whole microbiota is FMT, but FMT does have limitations, such as variable methods, esthetics consideration and safety concerns. The most obvious methodology difference of FMT between the current era and ancient era is based on the centrifugation, cryopreservation and automatic purification. How to preserve FMT materials remains a methodological challenge (Hale et al., 2016). Freshly collected feces can be immediately used, but not stored. The frozen microbiota is prepared with modern cryopreservation. The efficacy of fresh and frozen fecal materials has no significantly difference (Tang et al., 2017), but this finding is mainly from some trials on CDI treatment (Hamilton et al., 2012; Lee et al., 2016). In a double-blind study (Jiang et al., 2017), 72 patients with $\mathrm{CDI}$ were randomized to receive fresh, 
Table 1. The important events using fecal microbiota transplantation in history

\begin{tabular}{|c|c|}
\hline History of fecal microbiota transplantation (FMT) & Significance of the events \\
\hline $\begin{array}{l}\text { The fourth century (Ge 2000; Zhang et al., } 2012 \mathrm{~b} \text { ) } \\
\text { Ge Hong, a Chinese doctor described the rescue for serious food poisoning, } \\
\text { fever, diarrhea by drinking fecal water or fermented fecal matter in the book } \\
\text { "Zhou Hou Bei Ji Fang" }\end{array}$ & $\begin{array}{l}\text { The clear methods and indications supported the wide } \\
\text { practice in the following } 1,700 \text { years in China }\end{array}$ \\
\hline $\begin{array}{l}1590 \text { (Li 2011; Zhang et al., 2012b) } \\
\text { Li Shizhen, a Chinese doctor described more than } 20 \text { conditions effectively } \\
\text { treated by fecal water or fermented fecal matter in the book "Ben Cao Gang } \\
\text { Mu" }\end{array}$ & $\begin{array}{l}\text { The most complete record in medical use of fecal matter } \\
\text { in traditional human medicine }\end{array}$ \\
\hline $\begin{array}{l}1958 \text { (Eiseman et al., 1958) } \\
\text { Eiseman et al. from America successful treatment for pseudomenbraneous } \\
\text { colitis using fecal water by enema }\end{array}$ & The first report of FMT in English literature \\
\hline $\begin{array}{l}1989 \text { (Bennet and Brinkman 1989; Borody et al., 1989) } \\
\text { Bennet and Brinkman from America reported success by fecal water enema } \\
\text { for Bennet's ulcerative colitis; Borody et al. in Australia reported fecal water } \\
\text { enema in } 55 \text { patients with constipation, IBS and IBD }\end{array}$ & They broadened the use of FMT in intestinal diseases \\
\hline $\begin{array}{l}2012 \text { (Hamilton et al., 2012) } \\
\text { Hamilton et al. from America reported the method and efficacy of using frozen } \\
\text { fecal microbiota for C. difficile infection }\end{array}$ & The improved methodology for storing fecal microbiota \\
\hline $\begin{array}{l}2012 \text { (Vrieze et al., 2012) } \\
\text { Vrieze et al. from the Netherland reported the FMT in metabolic syndrome }\end{array}$ & The evidence to use FMT in changing insulin sensitivity \\
\hline $\begin{array}{l}2013 \text { (Surawicz et al., 2013) } \\
\text { FMT was recommended for the treatment of the third occurrence of } C \text {. difficle } \\
\text { infection in guideline }\end{array}$ & FMT was not folk remedy in America since 2013 \\
\hline $\begin{array}{l}2013 \text { (Zhang et al., 2013) } \\
\text { Zhang et al. from China reported the FMT through mid-gut in severe } \\
\text { fistulizing Crohn's disease with abdominal inflammatory mass }\end{array}$ & $\begin{array}{l}\text { The evidence to use FMT from enteral disease to severe } \\
\text { infection within abdominal cavity }\end{array}$ \\
\hline $\begin{array}{l}2015 \text { (Cui et al., } 2015 b) \\
\text { Cui et al. from China reported the automatic purification of microbiota from } \\
\text { stool and the step-up FMT strategy }\end{array}$ & $\begin{array}{l}\text { The modernized process of FMT and improved } \\
\text { recognition on FMT strategy }\end{array}$ \\
\hline $\begin{array}{l}2016 \text { (Kao et al., 2016) } \\
\text { Kao et al. in Canada reported the FMT for hepatic encephalopathy }\end{array}$ & Provides an evidence to use FMT for a liver disease \\
\hline $\begin{array}{l}2016 \text { (Kakihana et al., 2016) } \\
\text { Fujioka et al. from Japan reported the FMT for acute graft-versus-host } \\
\text { disease (GvHD) of the gut }\end{array}$ & The new option for anti-GvHD by FMT \\
\hline $\begin{array}{l}2017 \text { (He et al., 2017a) } \\
\text { He et al. from China reported the FMT for epilepsy }\end{array}$ & $\begin{array}{l}\text { Provides an evidence to use FMT for a neurological } \\
\text { disease }\end{array}$ \\
\hline
\end{tabular}

frozen or lyophilized FMT product via colonoscopy. The cure rate $(25 / 25,100 \%)$ was the highest in the group receiving fresh product, lowest $(16 / 23,78 \%)$ in the lyophilized group and intermediate $(20 / 24)$ in the frozen group. The frozen materials lost a large proportion of bacteria and decreased its efficacy in treating IBD (Cui et al., 2015a, b). This is the reason why the FMT using fresh materials is recommended in our center (He et al., 2017a, b; Zhang et al., 2017). The high clinical efficacy of fresh FMT is also observed in other centers (Uygun et al., 2017). Therefore, the clinical options should refer to the preservation methods of fecal microbiota when necessary.

\section{FROM FMT TO SELECTIVE MICROBIOTA TRANSPLANTATION}

It sounds an easy job for patients to understand the transplantation of microbiota into gut. The recent survey (Xu et al., 2016) on patients' attitude showed that $56.19 \%$ of 105 patients with Crohn's disease presented satisfactory clinical efficacy and $74.29 \%$ were willing to receive the second FMT. Additionally, 89.52\% (94/105) showed their willingness to recommend FMT to other patients. This study for the first time demonstrated that patients with Crohn's disease are willing to receive FMT due to its efficacy. Also, several cost-efficacy 
Figure 1. The changing of using microbial cells to treat human diseases.

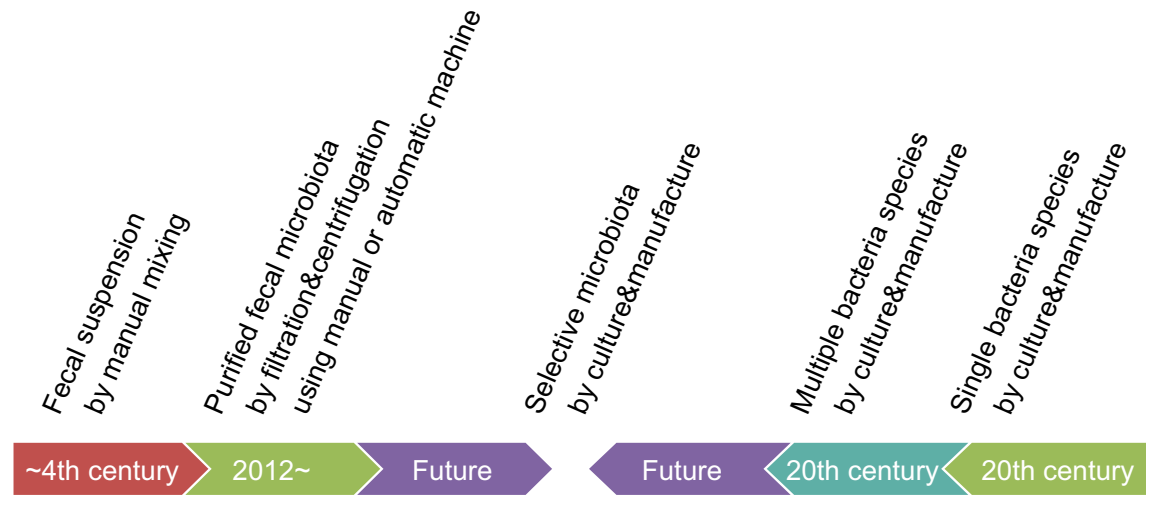

Microbiota transplant

Probiotics treatment

Efficacy changing trend

analyses of FMT for CDI in America (Konijeti et al., 2014; Varier et al., 2015), Canada (Waye et al., 2016), Australia (Merlo et al., 2016) and France (Baro et al., 2017) and IBD in China (Zhang et al., 2017) have demonstrated its significant advantage in reducing medical and social costs.

However, it is not easy for patients to accept the microbiota transplantation into organs beyond gastrointestinal tract. The accumulating evidences have shown a potential role of microbiota in extra-intestinal sites, such as vagina (Klatt et al., 2017), sinus (Schwartz et al., 2016), urinary tract (Tariq et al., 2017) and skin (Chu et al., 2017a, b). Therefore, the research in the future should focus on the specific use of microbiota in different organs (Hoffmann et al., 2017a, b), a strategy called selective microbiota transplantation (SMT). When SMT is used in gut for simulation of FMT, it can be named as mini-FMT. The possible applications of microbiota transplantation in human disease are shown in the Table 2.

Therefore, microbiota transplantation includes the whole profile of microbiota transplantation (e.g., FMT and vaginal microbiota transplantation) and the SMT for the stimulation of the whole profile of microbiota (e.g., the intermediate composition of bacteria between traditional probiotics and whole profile of microbiota). SMT should be promising in precision medicine.

\section{DELIVERING WAYS FOR MICROBIOTA TRANSPLANT}

Delivering ways for microbiota transplantation (Fig. 2) include the upper gut, mid-gut and lower gut (Peng et al., 2016). Oral intake of microbiota capsules is a mean of delivery through the upper gut (Youngster et al., 2014; Lee et al., 2016). Selected microbiota can be made into suspension or powder forms. The microbiota suspension can be infused into the small intestine beyond the second duodenal segment through endoscopy (Zhang et al., 2012a), nasojejunal tube (Cui et al., 2015a, b), mid-gut transendoscopic enteral tubing (TET) (Long et al., 2018), small intestine stoma or percutaneous endoscopic gastro-jejunostomy (PEG-J) (Ni et al., 2016; Peng et al., 2016). The TET through mid-gut is a novel, convenient and safe procedure for microbiota transplantation that results in a high degree of patients' satisfaction (Long et al., 2018). Fecal microbiota can be also delivered to the lower gut through colonoscopy, enema, distal ileum stoma, colostomy and colonic TET (Peng et al., 2016). Among them, colonic TET does not affect the patients' life quality. And $98.1 \%$ of cases $(53 / 54)$ were satisfied with FMT delivered through colonic TET. The colonic TET is recommended for patients who need frequent FMTs or FMT combined with other medications. For each delivering way, the aesthetic factors, psychology and privacy should be considered.

Two deaths have been reported associated with FMT delivering procedures though mid-gut (Baxter et al., 2015; Goldenberg et al., 2018). The two deaths had aspiration and died of pneumonia after mid-gut FMT. This complication can be avoided by the following clinical work-flow for mid-gut delivering: (1) Fasting for at least $4 \mathrm{~h}$ before FMT, and increasing gastrointestinal motility using metoclopramide $10 \mathrm{mg}$ by i.m. $1 \mathrm{~h}$ before FMT; (2) Nasojejunal tube should be inserted if anaesthesia is not suitable for endoscopy or the patient's condition is critical; (3) Keeping the patient in a sitting position for mid-gut delivery tube if the patient's condition permits and has the inserted tube; (4) Keeping the patient in reverse Trendelenburg and incline position $\left(>30^{\circ}\right)$ during endoscopy under anaesthesia, whereas a horizontal position should be avoided; (5) Ensuring patient's psychological well-being, through patient informed consent, detailed explanation on FMT and monitored anesthesia care during the procedure. It is advisable that patients do not witness the infusion during the procedure.

\section{LABORATORY PREPARATION OF FECAL MICROBIOTA}

The laboratory preparation, critical for a successful FMT, can be classified into "rough filtration (RF)", "filtration plus 
centrifugation (FPC)", "microfiltration plus centrifugation (MPC)" (He et al., 2017a, b). For example, the method in Hamilton's report in 2012 could be called as FPC (Hamilton et al., 2012), and the automatic method using purification system based on GenFMTer (FMT Medical, Nanjing, China) as MPC (He et al., 2017a, b) that can improve the standardization of the laboratory processes and avoid the technicians' exposure to fecal matter.

A recent study (Chu et al., 2017a, b) reported that some preparation methods can damage the content of living fecal microbes and the suitability of clinical fecal materials. Faecalibacterium prausnitzii-an anti-inflammatory commensal bacterium linked to inflammatory bowel disease-decreases once exposed to oxygen. Actually, those manual preparations are generally finished within six hours (Cammarota et al., 2017)_-"six-hour FMT protocol". With an automatic purification system and close cooperation between the laboratory technicians and clinicians, we have shortened the time "from defecation to infusion" or "from defecation to freezing" to one hour (Cui et al., 2016; Cammarota et al., 2017). This "one-hour FMT protocol" greatly improves the clinical response and cost-effectiveness of FMT for IBD patients according to the reports from China and others countries (Cui et al., 2015a, b; He et al., 2017a, b; Uygun et al., 2017; Zhang et al., 2017). Practitioners can easily master this "one-hour FMT protocol" using automatic purification system based on GenFMTer.

\section{SAFETY AND QUALITY CONTROL OF BENEFICIAL MICROBIOTA}

FMT related adverse events should be prevented in specific cases, especially those with poor immune status (Fischer et al., 2016a, b). During middle gut FMT, inappropriate techniques and procedures of infusing microbiota into the small bowel may cause adverse events, including nausea, vomiting and aspiration (Gweon et al., 2016; Furuya-Kanamori et al., 2017). With X-ray fluoroscopy or other non-invasive techniques, a nasojejunal tube should be inserted into the patient's intestine when the patient is at high risk of aspiration under anesthesia. Diarrhea and fever may occur within three hours after FMT, but this generally does not require use of medications (Cui et al., 2015a, b).

The safety in a long term should be considered, though evidence is solid so far. A woman developed new-onset obesity after receiving stool from a healthy but overweight donor (Alang and Kelly 2015). The potential cardiometabolic diseases, autoimmune diseases and neurological diseases have been discussed (Brandt et al., 2012; Kelly et al. 2015). Wong et al. (2017) reported that the fecal microbiota from patients with colon cancer promoted tumorigenesis in germfree and carcinogenic mice. Therefore, the strict donor screening should be conducted to prevent the disease transmission through FMT. The American Gastroenterological Association (AGA) is using data from national registry to work out a long term program that evaluates the risks and benefits of FMT for CDI (Kelly et al., 2017). The FmtBank (www.fmtbank.org) is carrying out a non-profit FMT research plan in China (China Microbiota Transplantation System) (Cui and Zhang 2018), covering the treatment decision, therapy, evaluation and safety in a short term and a ten-year follow-up.

\section{STRATEGY OF USING FMT: STEP-UP FMT STRATEGY}

The primary and secondary cure rate of fresh FMT for CDI is $91 \%$ and $98 \%$, respectively (Brandt et al., 2012). In an RCT study, these two rates become $81 \%$ and $94 \%$ of resolution of CDI after the first FMT and repeat FMTs (van Nood et al., 2013). The frozen FMT has been proven to have similar efficacy for treating CDI (Hamilton et al., 2012; Lee et al., 2016). An analysis based on 80 patients demonstrates that FMT is safe in immunocompromised cases (Kelly et al., 2014). A multivariable analysis (Fischer et al., 2016a, b) demonstrates that predictors of early FMT failure include severe or severe/complicated CDI, inpatient status during FMT, and previous CDI-related hospitalization.

Severe and severe/complicated CDI can result in intensive care unit admission, sepsis, toxic megacolon and even death. For them, colectomy is the standard treating strategy but it has a mortality of about $50 \%$. Fischer et al. reported (Fischer et al., 2015) that $29 \mathrm{CDI}$ patients at high risk of

Table 2. Possible usage of microbiota transplantation in human diseases

\begin{tabular}{|c|c|c|c|c|}
\hline Types & Sites & $\begin{array}{l}\text { Microbiota } \\
\text { profile }\end{array}$ & Suitable dosage forms & Possible management in policy \\
\hline FMT & Microbiota to gut & Whole & Pill, suspension & Medical technology or drug \\
\hline $\begin{array}{l}\text { SMT/mini- } \\
\text { FMT }\end{array}$ & Microbiota to gut & Selected & Pill, powder, suspension & Medical technology or drug \\
\hline SMT & Microbiota to sinus & Selected & $\begin{array}{l}\text { Powder, spray, } \\
\text { suspension }\end{array}$ & $\begin{array}{l}\text { Medical technology, drug or heath } \\
\text { products }\end{array}$ \\
\hline SMT & Microbiota to vagina & Selected & Pill, powder, suspension & Medical technology or drug \\
\hline SMT & $\begin{array}{l}\text { Vaginal microbiota to } \\
\text { skin }\end{array}$ & Selected/whole & $\begin{array}{l}\text { Powder, spray, } \\
\text { suspension }\end{array}$ & $\begin{array}{l}\text { Medical technology, drug or heath } \\
\text { products }\end{array}$ \\
\hline
\end{tabular}




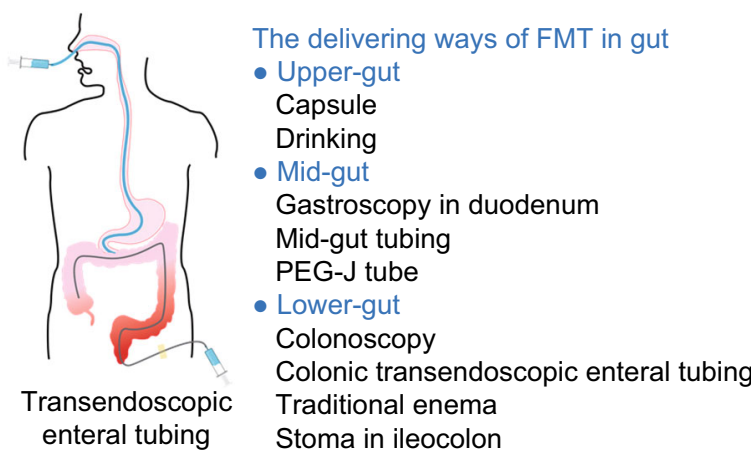

Figure 2. The delivering ways of microbiota transplantation in gastrointestinal tract.

colectomy underwent FMT plus vancomycin for severe complicated CDI. Single FMT was performed in $62 \%$, and multiple FMTs in $38 \%$ of patients (two FMTs in $31 \%$ and three FMTs in $7 \%$ of patients). FMT and continued vancomycin in selected patients increased the cure rate.

FMT can be performed for CDI with good efficacy, but the evidence for IBD and other diseases is more controversial. Paramsothy et al. (2017) reported that FMT with intensive doses and multiple donors induced clinical remission and endoscopic improvement in active ulcerative colitis and this treatment was associated with distinct microbial changes. $\mathrm{He}$ et al. recently reported that the second fresh FMT was an effective and safe treatment to maintain clinical response in Crohn's disease three months after the first FMT (He et al., 2017a, b). "One-hour FMT protocol" was reformed FMT in this study. All patients were suggested to receive an initial FMT followed by repeated FMTs every three months. Then $68.0 \%(17 / 25)$ and $52.0 \%$ (13/25) of patients achieved clinical response and clinical remission at three months post the initial FMT, respectively. The proportion of patients at 6 months, 12 months and 18 months achieving sustained clinical remission after sequential FMTs was 48.0\% (12/25), $32.0 \%(8 / 25)$ and $22.7 \%(5 / 22)$, respectively; $9.5 \%(2 / 21)$ achieved radiological healing and $71.4 \%$ (15/21) achieved radiological improvement. The conclusion could be made that multiple fresh FMTs induces and maintains clinical remission in Crohn's disease complicated with abdominal inflammatory mass.

In a recent pilot study (Cui et al., 2015a, b), 8 of 14 (57.1\%) patients achieved clinical improvement and were able to stop steroids use following step-up FMT. Among the 8 responders, $5(35.7 \%)$ received one FMT therapy, $1(7.1 \%)$ received two FMTs, and $2(14.2 \%)$ received two FMTs plus a scheduled course of steroids; 6 patients $(42.9 \%)$ failed to meet the clinical improvement criteria and maintained steroid dependence, though 3 patients experienced transient or partial improvement. No severe adverse events occurred during treatment and follow-up. Step-up FMT strategy as a holistic integrative concept (Fan 2017) focuses on the

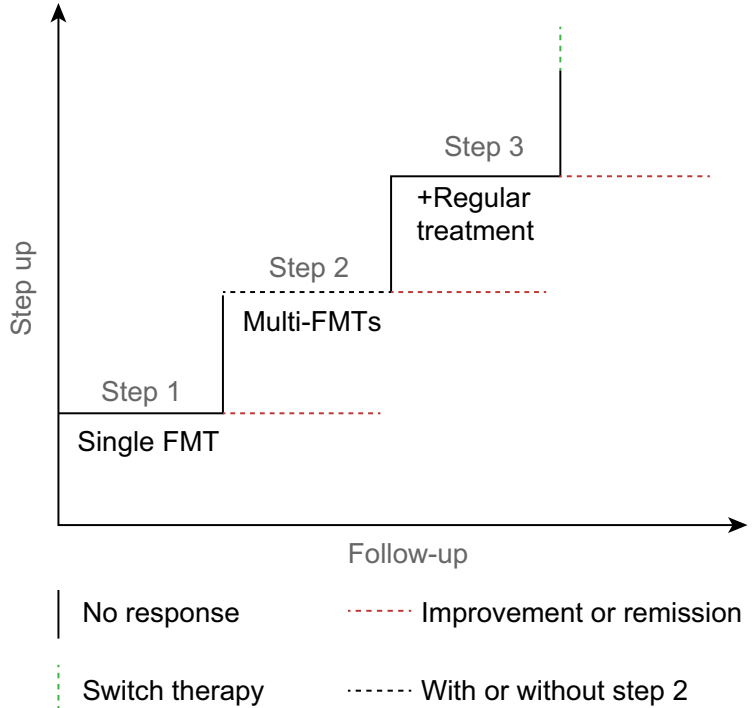

Figure 3. The step-up FMT strategy.

specificity of patients with steroid-dependent IBD (Cui et al., 2015a, b, 2016). We further refined the step-up FMT strategy for more than 3,000 cases with CDI, IBD and other disorders.

As shown in Fig. 3, the step-up FMT strategy consists of three parts: step 1 refers to single FMT; step 2 refers to multiFMTs $(\geq 2)$; step 3 refers to the FMT combined with regular medication (such as steroids, cyclosporine, anti-TNF- $\alpha$ antibody, total enteral nutrition) after the failure of step 1 or step 2. The efficacy of each step is enhanced by the measures in the next step. Medication is used at step 3 because the reconstructed gut microbiota may alter the host's immune status, intestinal barrier, and the sensitivity to regular medicine. This step-up FMT strategy is best indicated for patients with refractory IBD and immune-related diseases (Cui et al., 2015a, b, 2016), severe or complicated CDI (Fischer et al., 2015), especially when patients do not respond to regular medications.

Increasing evidence highlighted the necessity to formulate a treatment ladder with step 1, step 2 and step 3 (Fig. 3). Most commonly, step 1 involves a single FMT for treating CDI or refractory intestinal infection (Surawicz et al., 2013; Wei et al., 2016). The step 2 refers to multi-FMTs and is commonly indicated to treat patients with IBD (Cui et al., 2015a, b, 2016) and partially refractory CDI (Lee et al., 2014). Recently, Suskind et al. reported nine cases of Crohn's disease undergoing multiple FMTs through the nasojejunal tube (Suskind et al., 2015). 77.8\% (7/9) achieved clinical remission two weeks later, and five patients stopped additional medication 12 weeks later. Seth et al. (2016) reported a case of ulcerative colitis in India using multiple FMTs who maintained both clinical and endoscopic remission for more than eight months. Liu et al. (2017) reported multiple FMTs induced remission in 17 of 19 infants with infantile allergic colitis. 
The strategy using steroid after multiple FMTs (e.g., step 3) for steroid-dependent IBD patients has gained more support from clinical researches. Shimizu et al. (2016) reported that one child with ulcerative colitis, who was dependent on high steroid doses and did not respond to antitumor necrosis factor alpha (anti-TNF- $\alpha$ ) treatment, achieved clinical remission and low-dose steroid dependence after multiple FMTs. Its efficacy could also be found in steroidineligible severe alcoholic hepatitis (Philips et al., 2017) and steroid-resistant acute GvHD (Kakihana et al., 2016). These reports, including Fisher's report on severe CDI (Fischer et al., 2015), have given us a lens to see the potential of this new therapy in treating more microbiota-related diseases, especially those refractory conditions.

\section{NOVEL STRATEGY OF USING MICROBIOTA TO TREAT CANCER}

The increasing researches on immunotherapy, chemical therapy and radiation therapy after remodeling microbiota were reported as promising strategy to treat cancer in recent years. A new research found that gut microbiome improved efficacy of PD-1-based immunotherapy against epithelial tumors (Routy et al., 2018), implying that FMT can be used to fight against cancer. A significant association has been observed between commensal microbial composition and clinical response of anti-PD-L1 therapy in metastatic melanoma patients (Matson et al., 2018). Responders to anti-PDL1 therapy contain abundant bacterial species like Bifidobacterium longum, Collinsella aerofaciens and Enterococcus faecium. Anti-PD-L1 therapy in germ-free mice models with fecal materials from responding patients showed stronger tumor control, augmented $\mathrm{T}$ cell responses, and better efficacy. Another study (Gopalakrishnan et al., 2018) also demonstrated enhanced systemic immunity and favorable gut microbiome profile in patients showing good response to PD-1 immunotherapy, as well as in germ-free mice receiving fecal transplants from responding patients. Food and Drug Administration (FDA) has approved indications of anti-PD-1 and anti-PD-L1 therapies in cancer based on some registered trials (Gong et al., 2018). Another study also showed that gut microbiota could affect anticancer response to immunotherapy with CTLA-4 (Vetizou et al., 2015). The bioinformatic and functional studies demonstrated that Fusobacterium nucleatum enhanced the resistance of colorectal cancer to chemotherapy (Yu et al., 2017). Enterococcus hirae and Barnesiella intestinihominis can strengthen Cyclophosphamide-induced therapeutic immunomodulatory effects in cancer (Daillere et al., 2016). Microbiota could be modified in clinical practice to improve its efficacy and reduce the toxic burden of these compounds (Alexander et al., 2017). The effect of radiation on the gut microbiota, and the clinical implications of a modified microbial balance after radiotherapy are now beginning to emerge (Ferreira et al., 2014). FMT could mitigate radiation-

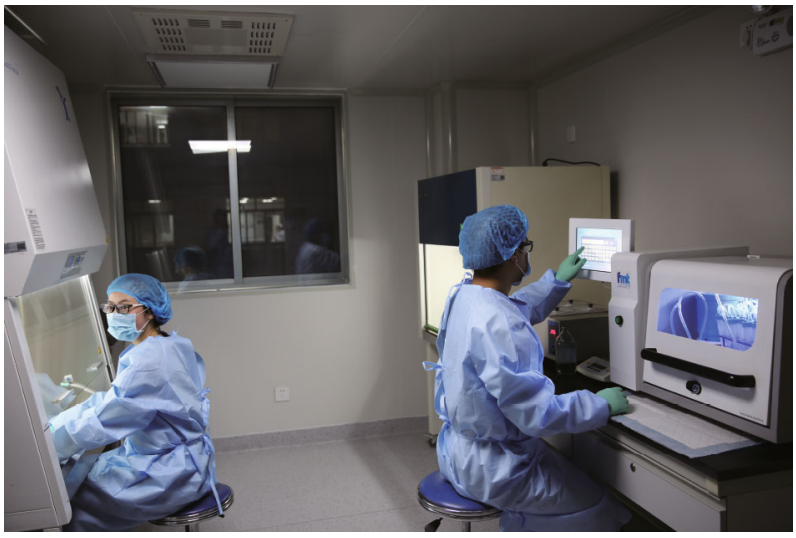

Figure 4. The GMP laboratory for preparation of fecal microbiota.

induced toxicity and increase the survival rate of irradiated mice. In this process, the peripheral white blood cell counts, gastrointestinal tract function and intestinal epithelial integrity were improved (Cui et al., 2017). These human, animal and in vitro studies suggest that step-up FMT may be a promising strategy in modulating cancer progression and drug response. In the new era of using selected microbiota for transplantation, the strategy of using SMT for cancer treatment should be same as step-up FMT.

\section{THE UPDATED SAFETY AND MONITORING OF FMT}

Serious adverse events can be caused by contaminated microbes in the donor stool. Hence, the laboratory preparation of FMT materials should meet the requirements of that the Good Manufacturing Practice (GMP) set for pharmaceutical companies to manufacture oral medications (Fig. 4). The unqualified human, animals, or biological samples must be excluded. Stools from donors known to the physicians or patients still need consistent screening to rule out infectious pathogens. Thus, a rapid, accurate and convenient fecal pathogen detection method is essential (Hoffmann et al., 2017a, b). To achieve a better traceability, donor fecal samples should be stored in deep cryopreservation for at least two years (Cui et al., 2016). Though FMT-related short term adverse events are in low incidence and mild (Wang et al., 2016), the long-term evaluation on FMT safety should be performed. This is the significance of national register for 10 years of evaluation of FMT in America (Kelly et al., 2017) and China Microbiota Transplantation System. In addition, government authorities must prioritize development of appropriate and effective regulation of FMT to safeguard patients and donors, promote related research and avoid abuse of the treatment (Ma et al., 2017).

\section{CONCLUSIONS}

In conclusion, the main changing concept of using microbial cells is to use microbiota as a holistic integrity. Emerging 
evidence on FMT revolutionizes our understanding on the mechanism and treatment of microbiota-related diseases. It is time to end the very crude stool transplant in humans. It is time to develop standardized FMT into a mainstream therapeutic option to bring benefits to more patients. The conditions of FMT will cover more diseases beyond recurrent CDI. SMT in specific organ will be a promising therapeutic choice in the near future. The strategy of using microbiota should attract more attention and become widely acceptable in biomedicine research and clinical decision-making.

\section{ACKNOWLEDGEMENTS}

This work was supported by publically donated Intestine Initiative; Jiangsu Province Medicine Creation Team and Leading Talents project (Faming Zhang); National Natural Science Foundation of China (Grant Nos. 81670495 and 81600417) and National Center for Clinical Research of Digestive System Diseases (2015BAI13B07).

\section{FMT-STANDARDIZATION STUDY GROUP}

The FMT-standardization Study Group co-authors contributed to the research, practice and education of the new concept, advanced methodology and specific strategy of FMT. The members of the Study Group are as follows: Baisui Feng from The Second Affiliated Hospital of Zhengzhou University; Dongfeng Chen from Daping Hospital of The Third Military Medical University; Jianlin Ren from Zhongshan Hospital of Xiamen University; Mingming Deng from The Affiliated Hospital of Southwest Medical University; Ning Li from The Tenth People's Hospital of Tongji University; Pengyuan Zheng from The Fifth Affiliated Hospital of Zhengzhou University; Qing Cao from Shanghai Children's Medical Center; Shaoqi Yang from General Hospital of Ningxia Medical University; Xingxiang He from The First Affiliated Hospital of Guangdong Pharmaceutical University; Yu Liu from Sir Run Run Hospital of Nanjing Medical University; Yuqiang Nie and Yongjian Zhou from Guangzhou First People's Hospital of Guangzhou Medical University; Daiming Fan, Kaichun Wu and Yongzhan Nie from Xijing Hospital of Digestive Diseases; Guozhong Ji, Pan Li, Bota Cui and Faming Zhang from The Second Affiliated Hospital of Nanjing Medical University.

\section{ABBREVIATIONS}

AD, Anno Domini; CDI, Clostridium difficile infection; FDA, Food and Drug Administration; FMT, fecal microbiota transplantation; GMP, good manufacturing practice; GvHD, graft-versus-host disease; IBS, irritable bowel disease; IBD, inflammatory bowel disease; PEG-J, percutaneous endoscopic gastro-jejunostomy; PD-1, programmed death-1; SMT, selective microbiota transplantation; TNF, tumor necrosis factor.

\section{COMPLIANCE WITH ETHICS GUIDELINES}

Faming Zhang, Bota Cui and Pan Li contributed to the invention and development of GenFMTer. Faming Zhang contributed to the invention of TET. Xingxiang He, Yuqiang Nie, Kaichun Wu, Daiming Fan and all of the other FMT-standardization Study Group members declare that they have no conflict of interest. This article does not contain any studies with human or animal subjects performed by the any of the authors.

\section{OPEN ACCESS}

This article is distributed under the terms of the Creative Commons Attribution 4.0 International License (http://creativecommons.org/ licenses/by/4.0/), which permits unrestricted use, distribution, and reproduction in any medium, provided you give appropriate credit to the original author(s) and the source, provide a link to the Creative Commons license, and indicate if changes were made.

\section{REFERENCES}

Alang N, Kelly CR (2015) Weight gain after fecal microbiota transplantation. Open Forum Infect Dis 2:ofv004

Alexander JL, Wilson ID, Teare J, Marchesi JR, Nicholson JK, Kinross JM (2017) Gut microbiota modulation of chemotherapy efficacy and toxicity. Nat Rev Gastroenterol Hepatol 14:356-365

Andrews PJ, Borody TJ (1993) "Putting back the bugs": bacterial treatment relieves chronic constipation and symptoms of irritable bowel syndrome. Med J Aust 159:633-634

Bajaj JS, Kassam Z, Fagan A, Gavis EA, Liu E, Cox IJ, Kheradman R, Kheradman R, Heuman D, Wang J et al (2017) Fecal microbiota transplant from a rational stool donor improves hepatic encephalopathy: a randomized clinical trial. Hepatology 66:1727-1738

Bak SH, Choi HH, Lee J, Kim MH, Lee YH, Kim JS, Cho YS (2017) Fecal microbiota transplantation for refractory Crohn's disease. Intest Res 15:244-248

Baro E, Galperine T, Denies F, Lannoy D, Lenne X, Odou P, Guery B, Dervaux B (2017) Cost-effectiveness analysis of five competing strategies for the management of multiple recurrent community-onset Clostridium difficile infection in France. PLOS ONE 12: e0170258

Baxter M, Ahmad T, Colville A, Sheridan R (2015) Fatal aspiration pneumonia as a complication of fecal microbiota transplant. Clin Infect Dis 61:136-137

Bennet JD, Brinkman M (1989) Treatment of ulcerative colitis by implantation of normal colonic flora. Lancet 1:164

Borody TJ, George L, Andrews P, Brandl S, Noonan S, Cole P, Hyland L, Morgan A, Maysey J, Moore-Jones D (1989) Bowelflora alteration: a potential cure for inflammatory bowel disease and irritable bowel syndrome. Med J Aust 150:604

Brandt LJ, Aroniadis OC, Mellow M, Kanatzar A, Kelly C, Park T, Stollman N, Rohlke F, Surawicz C (2012) Long-term follow-up of colonoscopic fecal microbiota transplant for recurrent Clostridium difficile infection. Am J Gastroenterol 107:1079-1087

Brodmann T, Endo A, Gueimonde M, Vinderola G, Kneifel W, de Vos WM, Salminen S, Gomez-Gallego C (2017) Safety of novel microbes for human consumption: practical examples of assessment in the European Union. Front Microbiol 8:1725

Cammarota G, laniro G, Tilg H, Rajilic-Stojanovic M, Kump P, Satokari R, Sokol H, Arkkila P, Pintus C, Hart A et al (2017) European consensus conference on faecal microbiota transplantation in clinical practice. Gut 66:569-580 
Chu DM, Ma J, Prince AL, Antony KM, Seferovic MD, Aagaard KM (2017a) Maturation of the infant microbiome community structure and function across multiple body sites and in relation to mode of delivery. Nat Med 23:314-326

Chu ND, Smith MB, Perrotta AR, Kassam Z, Alm EJ (2017b) Profiling living bacteria informs preparation of fecal microbiota transplantations. PLOS ONE 12:e0170922

Cui B, Zhang F (2018) Fecal microbiota transplantation: understanding from holistic integrative view. AME Med J 3:1

Cui B, Feng Q, Wang H, Wang M, Peng Z, Li P, Huang G, Liu Z, Wu $P$, Fan $Z$ et al (2015a) Fecal microbiota transplantation through mid-gut for refractory Crohn's disease: safety, feasibility, and efficacy trial results. J Gastroenterol Hepatol 30:51-58

Cui B, Li P, Xu L, Zhao Y, Wang H, Peng Z, Xu H, Xiang J, He Z, Zhang $T$ et al (2015b) Step-up fecal microbiota transplantation strategy: a pilot study for steroid-dependent ulcerative colitis. J Transl Med 13:298

Cui B, Li P, Xu L, Peng Z, Xiang J, He Z, Zhang T, Ji G, Nie Y, Wu K et al (2016) Step-up fecal microbiota transplantation (FMT) strategy. Gut Microbes 7:323-328

Cui M, Xiao H, Li Y, Zhou L, Zhao S, Luo D, Zheng Q, Dong J, Zhao Y, Zhang X et al (2017) Faecal microbiota transplantation protects against radiation-induced toxicity. EMBO Mol Med 9:448-461

Daillere R, Vetizou M, Waldschmitt N, Yamazaki T, Isnard C, PoirierColame V, Duong CP, Flament C, Lepage P, Roberti MP et al (2016) Enterococcus hirae and Barnesiella intestinihominis facilitate cyclophosphamide-induced therapeutic immunomodulatory effects. Immunity 45:931-943

Dubilier N, McFall-Ngai M, Zhao L (2015) Microbiology: create a global microbiome effort. Nature 526:631-634

Eiseman B, Silen W, Bascom GS, Kauvar AJ (1958) Fecal enema as an adjunct in the treatment of pseudomembranous enterocolitis. Surgery 44:854-859

Fan D (2017) Holistic integrative medicine: toward a new era of medical advancement. Front Med 11:152-159

Ferreira MR, Muls A, Dearnaley DP, Andreyev HJ (2014) Microbiota and radiation-induced bowel toxicity: lessons from inflammatory bowel disease for the radiation oncologist. Lancet Oncol 15: e139-e147

Fischer M, Sipe BW, Rogers NA, Cook GK, Robb BW, Vuppalanchi R, Rex DK (2015) Faecal microbiota transplantation plus selected use of vancomycin for severe-complicated Clostridium difficile infection: description of a protocol with high success rate. Aliment Pharmacol Ther 42:470-476

Fischer M, Kao D, Kelly C, Kuchipudi A, Jafri SM, Blumenkehl M, Rex D, Mellow M, Kaur N, Sokol H et al (2016a) Fecal microbiota transplantation is safe and efficacious for recurrent or refractory Clostridium difficile infection in patients with inflammatory bowel disease. Inflamm Bowel Dis 22:2402-2409

Fischer M, Kao D, Mehta SR, Martin T, Dimitry J, Keshteli AH, Cook GK, Phelps E, Sipe BW, Xu H et al (2016b) Predictors of early failure after fecal microbiota transplantation for the therapy of Clostridium difficile infection: a multicenter study. Am J Gastroenterol 111:1024-1031

Furuya-Kanamori L, Doi SA, Paterson DL, Helms SK, Yakob L, McKenzie SJ, Garborg K, Emanuelsson F, Stollman N, Kronman MP et al (2017) Upper versus lower gastrointestinal delivery for transplantation of fecal microbiota in recurrent or refractory Clostridium difficile infection: a collaborative analysis of individual patient data from 14 studies. J Clin Gastroenterol 51:145-150

Ge H (2000) Zhou Hou Bei Ji Fang. Tianjin Science \& Technology Press, Tianjin

Gibson MK, Pesesky MW, Dantas G (2014) The yin and yang of bacterial resilience in the human gut microbiota. $\mathrm{J}$ Mol Biol 426:3866-3876

Gibson GR, Hutkins R, Sanders ME, Prescott SL, Reimer RA, Salminen SJ, Scott K, Stanton C, Swanson KS, Cani PD et al (2017) Expert consensus document: The International Scientific Association for Probiotics and Prebiotics (ISAPP) consensus statement on the definition and scope of prebiotics. Nat Rev Gastroenterol Hepatol 14:491-502

Goldenberg SD, Batra R, Batra R, Beales I, Digby-Bell JL, Irving PM, Kellingray L, Narbad A, Franslem-Elumogo N (2018) Comparison of different strategies for providing fecal microbiota transplantation to treat patients with recurrent Clostridium difficile infection in two english hospitals: a review. Infect Dis Ther LID. https://doi. org/10.1007/s40121-018-0189-y

Gong J, Chehrazi-Raffle A, Reddi S, Salgia R (2018) Development of PD-1 and PD-L1 inhibitors as a form of cancer immunotherapy: a comprehensive review of registration trials and future considerations. J Immunother Cancer 6:8

Gopalakrishnan V, Spencer CN, Nezi L, Reuben A, Andrews MC, Karpinets TV, Prieto PA, Vicente D, Hoffman K, Wei SC et al (2018) Gut microbiome modulates response to anti-PD-1 immunotherapy in melanoma patients. Science 359:97-103

Gweon TG, Kim J, Lim CH, Park JM, Lee DG, Lee IS, Cho YS, Kim SW, Choi MG (2016) Fecal microbiota transplantation using upper gastrointestinal tract for the treatment of refractory or severe complicated Clostridium difficile infection in elderly patients in poor medical condition: the first study in an Asian country. Gastroenterol Res Pract 2016:2687605

Hale VL, Tan CL, Niu K, Yang Y, Cui D, Zhao H, Knight R, Amato KR (2016) Effects of field conditions on fecal microbiota. J Microbiol Methods 130:180-188

Hamilton MJ, Weingarden AR, Sadowsky MJ, Khoruts A (2012) Standardized frozen preparation for transplantation of fecal microbiota for recurrent Clostridium difficile infection. Am J Gastroenterol 107:761-767

He Z, Cui BT, Zhang T, Li P, Long CY, Ji GZ, Zhang FM (2017a) Fecal microbiota transplantation cured epilepsy in a case with Crohn's disease: the first report. World J Gastroenterol 23:35653568

He Z, Li P, Zhu J, Cui B, Xu L, Xiang J, Zhang T, Long C, Huang G, Ji $\mathrm{G}$ et al (2017b) Multiple fresh fecal microbiota transplants induces and maintains clinical remission in Crohn's disease complicated with inflammatory mass. Sci Rep 7:4753

Hoffmann D, Palumbo F, Ravel J, Roghmann MC, Rowthorn V, von Rosenvinge $E$ (2017a) Improving regulation of microbiota transplants. Science 358(80):1390-1391

Hoffmann DE, Palumbo FB, Ravel J, Rowthorn V, von Rosenvinge E (2017b) A proposed definition of microbiota transplantation for regulatory purposes. Gut Microbes 8:208-213

Jiang ZD, Ajami NJ, Petrosino JF, Jun G, Hanis CL, Shah M, Hochman L, Ankoma-Sey V, DuPont AW, Wong MC et al (2017) 
Randomised clinical trial: faecal microbiota transplantation for recurrent Clostridium difficile infection - fresh, or frozen, or lyophilised microbiota from a small pool of healthy donors delivered by colonoscopy. Aliment Pharmacol Ther 45:899-908 Johnsen PH, Hilpusch F, Cavanagh JP, Leikanger IS, Kolstad C, Valle PC, Goll R (2018) Faecal microbiota transplantation versus placebo for moderate-to-severe irritable bowel syndrome: a double-blind, randomised, placebo-controlled, parallel-group, single-centre trial. Lancet Gastroenterol Hepatol 3:17-24

Kakihana K, Fujioka Y, Suda W, Najima Y, Kuwata G, Sasajima S, Mimura I, Morita H, Sugiyama D, Nishikawa H et al (2016) Fecal microbiota transplantation for patients with steroid-resistant acute graft-versus-host disease of the gut. Blood 128:2083-2088

Kang DW, Adams JB, Gregory AC, Borody T, Chittick L, Fasano A, Khoruts A, Geis E, Maldonado J, McDonough-Means $S$ et al (2017) Microbiota transfer therapy alters gut ecosystem and improves gastrointestinal and autism symptoms: an open-label study. Microbiome 5:10

Kao D, Roach B, Park H, Hotte N, Madsen K, Bain V, Tandon P (2016) Fecal microbiota transplantation in the management of hepatic encephalopathy. Hepatology 63:339-340

Kellermayer R, Nagy-Szakal D, Harris RA, Luna RA, Pitashny M, Schady D, Mir SA, Lopez ME, Gilger MA, Belmont J et al (2015) Serial fecal microbiota transplantation alters mucosal gene expression in pediatric ulcerative colitis. Am J Gastroenterol 110:604-606

Kelly CR, Ihunnah C, Fischer M, Khoruts A, Surawicz C, Afzali A, Aroniadis O, Barto A, Borody T, Giovanelli A et al (2014) Fecal microbiota transplant for treatment of Clostridium difficile infection in immunocompromised patients. Am J Gastroenterol 109:10651071

Kelly CR, Kahn S, Kashyap P, Laine L, Rubin D, Atreja A, Moore T, Wu G (2015) Update on fecal microbiota transplantation 2015: indications, methodologies, mechanisms, and outlook. Gastroenterology 149:223-237

Kelly CR, Kim AM, Laine L, Wu GD (2017) The AGA's fecal microbiota transplantation national registry: an important step toward understanding risks and benefits of microbiota therapeutics. Gastroenterology 152:681-684

Khoruts A, Sadowsky MJ (2016) Understanding the mechanisms of faecal microbiota transplantation. Nat Rev Gastroenterol Hepatol 13:508-516

Klatt NR, Cheu R, Birse K, Zevin AS, Perner M, Noel-Romas L, Grobler A, Westmacott G, Xie IY et al (2017) Vaginal bacteria modify HIV tenofovir microbicide efficacy in African women. Science 356:938-945

Konijeti GG, Sauk J, Shrime MG, Gupta M, Ananthakrishnan AN (2014) Cost-effectiveness of competing strategies for management of recurrent Clostridium difficile infection: a decision analysis. Clin Infect Dis 58:1507-1514

Lee CH, Belanger JE, Kassam Z, Smieja M, Higgins D, Broukhanski G, Kim PT (2014) The outcome and long-term follow-up of 94 patients with recurrent and refractory Clostridium difficile infection using single to multiple fecal microbiota transplantation via retention enema. Eur J Clin Microbiol Infect Dis 33:1425-1428

Lee $\mathrm{CH}$, Steiner T, Petrof EO, Smieja M, Roscoe D, Nematallah A, Weese JS, Collins S, Moayyedi P, Crowther M et al (2016)
Frozen vs Fresh fecal microbiota transplantation and clinical resolution of diarrhea in patients with recurrent Clostridium difficile infection: a randomized clinical trial. JAMA 315:142-149 Li S (2011) Ben Cao Gang Mu. Huaxia Press, Beijing

Liu SX, Li YH, Dai WK, Li XS, Qiu CZ, Ruan ML, Zou B, Dong C, Liu $\mathrm{YH}, \mathrm{He}$ JY et al (2017) Fecal microbiota transplantation induces remission of infantile allergic colitis through gut microbiota reestablishment. World J Gastroenterol 23:8570-8581

Long C, Yu Y, Cui B, Jagessar AA, Zhang J, Ji G, Huang G, Zhang F (2018) A novel quick transendoscopic enteral tubing in mid-gut: technique and training with video. BMC Gastroenterol 18:37

Lynch SV, Pedersen O (2016) The human intestinal microbiome in health and disease. N Engl J Med 375:2369-2379

Ma Y, Liu J, Rhodes C, Nie Y, Zhang F (2017) Ethical issues in fecal microbiota transplantation in practice. Am J Bioeth 17:34-45

Madsen JS, Sorensen SJ, Burmolle M (2017) Bacterial social interactions and the emergence of community-intrinsic properties. Curr Opin Microbiol 42:104-109

Martz SL, Guzman-Rodriguez M, He SM, Noordhof C, Hurlbut DJ, Gloor GB, Carlucci C, Weese S, Allen-Vercoe E, Sun J et al (2017) A human gut ecosystem protects against $C$. difficile disease by targeting TcdA. J Gastroenterol 52:452-465

Matson V, Fessler J, Bao R, Chongsuwat T, Zha Y, Alegre ML, Luke JJ, Gajewski TF (2018) The commensal microbiome is associated with anti-PD-1 efficacy in metastatic melanoma patients. Science 359:104-108

Merlo G, Graves N, Brain D, Connelly LB (2016) Economic evaluation of fecal microbiota transplantation for the treatment of recurrent Clostridium difficile infection in Australia. J Gastroenterol Hepatol 31:1927-1932

Miller LE, Zimmermann AK, Ouwehand AC (2016) Contemporary meta-analysis of short-term probiotic consumption on gastrointestinal transit. World J Gastroenterol 22:5122-5131

Moayyedi P, Surette MG, Kim PT, Libertucci J, Wolfe M, Onischi C, Armstrong D, Marshall JK, Kassam Z, Reinisch W et al (2015) Fecal microbiota transplantation induces remission in patients with active ulcerative colitis in a randomized controlled trial. Gastroenterology 149:102-109.e6

Ni X, Fan S, Zhang Y, Wang Z, Ding L, Li Y, Li J (2016) Coordinated hospital-home fecal microbiota transplantation via percutaneous endoscopic cecostomy for recurrent steroid-dependent ulcerative colitis. Gut Liver 10:975-980

Paramsothy S, Kamm MA, Kaakoush NO, Walsh AJ, van den Bogaerde J, Samuel D, Leong RW, Connor S, Ng W, Paramsothy $R$ et al (2017) Multidonor intensive faecal microbiota transplantation for active ulcerative colitis: a randomised placebo-controlled trial. Lancet 389:1218-1228

Peng Z, Xiang J, He Z, Zhang T, Xu L, Cui B, Li P, Huang G, Ji G, Nie $Y$ et al (2016) Colonic transendoscopic enteral tubing: a novel way of transplanting fecal microbiota. Endosc Int Open 4:E610E613

Petrof EO, Gloor GB, Vanner SJ, Weese SJ, Carter D, Daigneault MC, Brown EM, Schroeter K, Allen-Vercoe E (2013) Stool substitute transplant therapy for the eradication of Clostridium difficile infection: 'RePOOPulating' the gut. Microbiome 1:3

Philips CA, Pande A, Shasthry SM, Jamwal KD, Khillan V, Chandel SS, Kumar G, Sharma MK, Maiwall R, Jindal A et al (2017) 
Healthy donor fecal microbiota transplantation in steroid-ineligible severe alcoholic hepatitis: a pilot study. Clin Gastroenterol Hepatol 15:600-602

Ren RR, Sun G, Yang YS, Peng LH, Wang SF, Shi XH, Zhao JQ, Ban YL, Pan F, Wang XH et al (2016) Chinese physicians' perceptions of fecal microbiota transplantation. World J Gastroenterol 22:4757-4765

Ren YD, Ye ZS, Yang LZ, Jin LX, Wei WJ, Deng YY, Chen XX, Xiao CX, Yu XF, Xu HZ et al (2017) Fecal microbiota transplantation induces hepatitis $B$ virus e-antigen $(\mathrm{HBeAg})$ clearance in patients with positive $\mathrm{HBeAg}$ after long-term antiviral therapy. Hepatology 65:1765-1768

Rossen NG, Fuentes S, van der Spek MJ, Tijssen JG, Hartman JH, Duflou A, Lowenberg M, van den Brink GR, Mathus-Vliegen EM, de Vos WM et al (2015) Findings from a randomized controlled trial of fecal transplantation for patients with ulcerative colitis. Gastroenterology 149(110-118):e4

Routy B, Le Chatelier E, Derosa L, Duong CPM, Alou MT, Daillère R, Fluckiger A, Messaoudene M, Rauber C, Roberti MP (2018) Gut microbiome influences efficacy of PD-1-based immunotherapy against epithelial tumors. Science 359:91-97

Schwartz JS, Peres AG, Mfuna EL, Cousineau B, Madrenas J, Desrosiers M (2016) Topical probiotics as a therapeutic alternative for chronic rhinosinusitis: A preclinical proof of concept. Am J Rhinol Allergy 30:202-205

Seth AK, Rawal P, Bagga R, Jain P (2016) Successful colonoscopic fecal microbiota transplantation for active ulcerative colitis: first report from India. Indian J Gastroenterol 35:393-395

Shimizu H, Arai K, Abe J, Nakabayashi K, Yoshioka T, Hosoi K, Kuroda M (2016) Repeated fecal microbiota transplantation in a child with ulcerative colitis. Pediatr Int 58:781-785

Spindelboeck W, Schulz E, Uhl B, Kashofer K, Aigelsreiter A, ZinkeCerwenka W, Mulabecirovic A, Kump PK, Halwachs B, Gorkiewicz $G$ et al (2017) Repeated fecal microbiota transplantations attenuate diarrhea and lead to sustained changes in the fecal microbiota in acute, refractory gastrointestinal graft-versus-hostdisease. Haematologica 102:e210-e213

Stallmach A, Anttila VJ, Hell M, Gwynn S, Merino-Amador P, Petrosillo N, Racil Z, Warren T, Wenisch C, Wilcox M (2018) Inflammatory bowel disease and Clostridium difficile infection: contrasting views of international clinical professionals. Z Gastroenterol LID. https://doi.org/10.1055/s-0044-100045

Starkel P, Leclercq S, de Timary P, Schnabl B (2018) Intestinal dysbiosis and permeability: the yin and yang in alcohol dependence and alcoholic liver disease. Clin Sci (Lond) 132:199-212

Surawicz CM, Brandt LJ, Binion DG, Ananthakrishnan AN, Curry SR, Gilligan PH, McFarland LV, Mellow M, Zuckerbraun BS (2013) Guidelines for diagnosis, treatment, and prevention of Clostridium difficile infections. Am J Gastroenterol 108:478-498 (quiz 499)

Suskind DL, Brittnacher MJ, Wahbeh G, Shaffer ML, Hayden HS, Qin X, Singh N, Damman CJ, Hager KR, Nielson H et al (2015) Fecal microbial transplant effect on clinical outcomes and fecal microbiome in active Crohn's disease. Inflamm Bowel Dis 21:556-563

Tang G, Yin W, Liu W (2017) Is frozen fecal microbiota transplantation as effective as fresh fecal microbiota transplantation in patients with recurrent or refractory Clostridium difficile infection: a meta-analysis. Diagn Microbiol Infect Dis 88:322-329

Tariq R, Pardi DS, Tosh PK, Walker RC, Razonable RR, Khanna S (2017) Fecal microbiota transplantation for recurrent Clostridium difficile infection reduces recurrent urinary tract infection frequency. Clin Infect Dis 65:1745-1747

Tian H, Ding C, Gong J, Ge X, McFarland LV, Gu L, Wei Y, Chen Q, Zhu W, Li J et al (2016) Treatment of slow transit constipation with fecal microbiota transplantation: a pilot study. J Clin Gastroenterol 50:865-870

Uygun A, Ozturk K, Demirci H, Oger C, Avci IY, Turker T, Gulsen M (2017) Fecal microbiota transplantation is a rescue treatment modality for refractory ulcerative colitis. Medicine (Baltimore) 96:e6479

van Nood E, Vrieze A, Nieuwdorp M, Fuentes S, Zoetendal EG, de Vos WM, Visser CE, Kuijper EJ, Bartelsman JF, Tijssen JG et al (2013) Duodenal infusion of donor feces for recurrent Clostridium difficile. N Engl J Med 368:407-415

Varier RU, Biltaji E, Smith KJ, Roberts MS, Kyle JM, LaFleur J, Nelson RE (2015) Cost-effectiveness analysis of fecal microbiota transplantation for recurrent Clostridium difficile infection. Infect Control Hosp Epidemiol 36:438-444

Vetizou M, Pitt JM, Daillere R, Lepage P, Waldschmitt N, Flament C, Rusakiewicz S, Routy B, Roberti MP, Duong CP et al (2015) Anticancer immunotherapy by CTLA-4 blockade relies on the gut microbiota. Science 350:1079-1084

Vindigni SM, Surawicz CM (2017) Fecal microbiota transplantation. Gastroenterol Clin North Am 46:171-185

Vrieze A, Van Nood E, Holleman F, Salojarvi J, Kootte RS, Bartelsman JF, Dallinga-Thie GM, Ackermans MT, Serlie MJ, Oozeer $R$ et al (2012) Transfer of intestinal microbiota from lean donors increases insulin sensitivity in individuals with metabolic syndrome. Gastroenterology 143:913-916.e7

Wang S, Xu M, Wang W, Cao X, Piao M, Khan S, Yan F, Cao H, Wang B (2016) Systematic review: adverse events of fecal microbiota transplantation. PLOS ONE 11:e0161174

Waye A, Atkins K, Kao D (2016) Cost averted with timely fecal microbiota transplantation in the management of recurrent Clostridium difficile infection in Alberta, Canada. J Clin Gastroenterol 50:747-753

Wei Y, Yang J, Wang J, Yang Y, Huang J, Gong H, Cui H, Chen D (2016) Successful treatment with fecal microbiota transplantation in patients with multiple organ dysfunction syndrome and diarrhea following severe sepsis. Crit Care 20:332

Wong SH, Zhao L, Zhang X, Nakatsu G, Han J, Xu W, Xiao X, Kwong TN, Tsoi H, Wu WK et al (2017) Gavage of fecal samples from patients with colorectal cancer promotes intestinal carcinogenesis in germ-free and conventional mice. Gastroenterology 153:1621-1633.e7

Wu W, Chen F, Liu Z, Cong Y (2016) Microbiota-specific Th17 cells: Yin and Yang in regulation of inflammatory bowel disease. Inflamm Bowel Dis 22:1473-1482

Xu R (2011) Chong Ding Tong Su Shang Han Lun. China Press of Traditional Chinese Medicine, Beijing

Xu L, Zhang T, Cui B, He Z, Xiang J, Long C, Peng Z, Li P, Huang G, Ji $G$ et al (2016) Clinical efficacy maintains patients' positive attitudes toward fecal microbiota transplantation. Medicine (Baltimore) 95:e4055 
Youngster I, Russell GH, Pindar C, Ziv-Baran T, Sauk J, Hohmann EL (2014) Oral, capsulized, frozen fecal microbiota transplantation for relapsing Clostridium difficile infection. JAMA 312:1772-1778

Yu T, Guo F, Yu Y, Sun T, Ma D, Han J, Qian Y, Kryczek I, Sun D, Nagarsheth $\mathrm{N}$ et al (2017) Fusobacterium nucleatum promotes chemoresistance to colorectal cancer by modulating autophagy. Cell 170(548-563):e16

Zhang F, Amateau SK, Khashab MA, Okolo PI III (2012a) Mid-gut stents. Curr Opin Gastroenterol 28:451-460

Zhang F, Luo W, Shi Y, Fan Z, Ji G (2012b) Should we standardize the 1,700-year-old fecal microbiota transplantation. Am J Gastroenterol 107:1755 (author reply p. 1755-1756)
Zhang FM, Wang HG, Wang M, Cui BT, Fan ZN, Ji GZ (2013) Fecal microbiota transplantation for severe enterocolonic fistulizing Crohn's disease. World J Gastroenterol 19:7213-7216

Zhang T, Xiang J, Cui B, He Z, Li P, Chen H, Xu L, Ji G, Nie Y, Wu K et al (2017) Cost-effectiveness analysis of fecal microbiota transplantation for inflammatory bowel disease. Oncotarget 8:88894-88903 